\title{
Produção e composição bromatológica da silagem de híbridos de milho sob duas alturas de corte
}

\author{
Wilian Henrique Diniz Buso ${ }^{1}$, Alan Soares Machado ${ }^{1}$, Taiz Borges Ribeiro ${ }^{1}$, Lidiane Oliveira \\ Silva ${ }^{1}$
}

${ }^{1}$ Instituto Federal de Educação, Ciência e Tecnologia Goiano, Campus Ceres, Ceres, Goiás, Brasil. E-mail:

wilian.buso@ifgoiano.edu.br, asm3201@hotmail.com, taiz2612@hotmail.com, lidiany_oliveira15@hotmail.com

Recebido: 10/05/2018; Aceito: 25/10/2018.

\section{RESUMO}

Objetivou-se avaliar a produção e composição químico-bromatológica da matéria original e da silagem de cinco híbridos de milho em duas alturas de corte. Utilizou-se o delineamento de blocos completos casualisados em esquema fatorial 5x2, cinco híbridos de milho (AGN30A95H, DKB399Y, DKB390Y, P3862H e TRUCK) e duas alturas de corte $(0,25$ e $0,50 \mathrm{~m})$ com três repetições. As plantas foram cortadas, picadas na ensiladeira e ensiladas em tubos de PVC. Para altura das plantas, os híbridos DKB399Y e P3862H diferiram $(\mathrm{P}<0,05)$ dos demais, apresentando maior altura $(2,35 \mathrm{~m})$. De forma geral, a composição bromatológica do material original e da silagem dos híbridos estudados esteve dentro dos parâmetros recomendados de silagem de qualidade. Todos os híbridos de milho apresentaram características favoráveis ao processo de ensilagem e as alturas de corte não interferiram na qualidade.

Palavras-chave: conservação, forragem, híbridos, nutrição, Zea mays.

\section{Production and bromatological composition of the silage of corn cultivars under two cutting heights}

\begin{abstract}
For production of silage it is important to identify and quantify the nutritional characteristics of the plant o evaluate the production and chemical-bromatological composition of the original matter and the five hybrids corn silage at two cutting heights. The respective silages were evaluated for same parameters. A randomized complete block design in a $5 \times 2$ factorial scheme, five maize cultivars (AGN30A95H, DKB399Y, DKB390Y, P3862H and TRUCK) and two cutting heights $(0.25$ and $0.50 \mathrm{~m})$ with three replicates were used. The plants were cut, chopped into the forage harvester and incubated in PVC tubes. Taking into account the plant height the cultivate DKB399Y and $\mathrm{P} 3862 \mathrm{H}$ differed $(\mathrm{P}<0.05)$ from other cultivars showing greater height $(2.35 \mathrm{~m})$. In general, the bromatological composition of the original material and the silage of the hybrids studied was within the parameters recommended quality silage. All corn cultivars showed favorable characteristics to the silage process and cutting heights not interfered in quality.
\end{abstract}

Keywords: conservation, forage, hybrids, nutrition, Zea mays. 


\section{Introdução}

A conservação de forragens, tanto na forma de feno como na forma de silagem, surge como alternativa para superar os problemas decorrentes de escassez de forragens no período de entressafra (seca). A redução das perdas e a inibição das fermentações secundárias são importantes metas a serem alcançadas, sendo que vários autores recomendam a ensilagem do milho com teor de matéria seca em torno de $30 \%$, baseado nas justificativas de maior produção de massa verde, facilidade no corte, eficiência na compactação e maior fragmentação dos grãos (Zopollatto et al., 2009; Oliveira et al., 2013).

A cultura do milho (Zea mays) é amplamente utilizada para produção de silagem devido ao seu elevado valor nutritivo para ruminantes, principalmente como fonte de energia. Além disso, possui todas as características necessárias para um processo fermentativo adequado quando armazenado no silo. $\mathrm{O}$ cultivar, a maturação no momento da ensilagem e o processo mecânico de corte influenciam nas características físicas e químicas de fermentação da silagem (Johnson et al., 2002).

O milho é uma das espécies mais utilizadas para produção de silagem devido à facilidade de cultivo, adaptabilidade, alta produção de massa, facilidade de fermentação no silo, bom valor energético e alto consumo pelos animais (Gimenes et al., 2006). Segundo Jaremtchuk et al. (2005), o uso de híbridos de milho mais produtivos e adaptados às condições locais tem sido apontado como responsável pelos maiores ganhos obtidos em produtividade. Neste contexto, a busca de híbridos de milho que sejam adaptados à região torna-se fator fundamental para obtenção de resultados satisfatórios do ponto de vista agronômico, zootécnico e econômico.

Segundo Van Soest (1994), a qualidade da silagem pode ser influenciada, entre outros fatores, pelo processo fermentativo da massa, uma vez que, durante a ensilagem, pode ocorrer redução do valor nutritivo pela respiração, fermentação aeróbia, processos de decomposição ou perdas de efluentes. De acordo com os mesmos autores, entre os parâmetros que determinam a qualidade da fermentação, estão os valores de $\mathrm{pH}$ associados ao teor de matéria seca e a concentração de nitrogênio amoniacal em relação ao nitrogênio total.

Ballard et al. (2001) relatam que a qualidade nutricional da silagem está relacionada com os componentes da parede celular, principalmente com os teores de fibra em detergente neutro (FDN) e fibra em detergente ácido (FDA). Os mesmos autores relatam ainda que, em estádios iniciais da cultura, esses teores são altos devido à baixa presença de amido na planta. Com o decorrer da maturidade fisiológica da planta, ocorre o aumento na quantidade de grãos e a presença do amido dissolve o teor de FDN e FDA da planta inteira de milho. As mudanças e/ou perdas durante a ensilagem são influenciadas pelas características da planta forrageira e estão também associadas às práticas de manejo, colheita e armazenamento (Santos et al., 2010)

$\mathrm{O}$ aumento na altura de corte pode melhorar os teores de energia e diminuir a concentração da FDN na silagem, pois, de acordo com Neumann et al. (2007), a parte basal do colmo apresenta maior concentração de FDN, havendo, assim, alteração na fração fibrosa da silagem. Ao aumentar a altura de corte no momento da ensilagem, há aumento da participação dos grãos na silagem, o que promove ganhos no valor nutricional (Caetano et al., 2012).

Diante do exposto, o presente trabalho objetivou avaliar a produção e composição químicobromatológica da matéria original e da silagem de cinco híbridos de milho em duas alturas de corte.

\section{Material e Métodos}

O experimento foi realizado no Setor de Agricultura e no Laboratório do Núcleo de Pesquisa em Gado Leiteiro (NPGL) do Instituto Federal Goiano - Campus Ceres-GO, situado na Rodovia GO 154, $\mathrm{km} 3$ (15 21' 03" S, 49 35' 37' W e altitude de $564 \mathrm{~m}$ ).

O solo do local foi classificado como Latossolo Vermelho Amarelo distrófico, apresentando as seguintes características químicas: $\mathrm{Ca}=2,4\left(\mathrm{cmol}_{\mathrm{c}} \mathrm{dm}^{-3}\right) ; \mathrm{Mg}=$ $1,3\left(\mathrm{cmol}_{\mathrm{c}} \mathrm{dm}^{-3}\right) ; \mathrm{k}=0,26\left(\mathrm{cmol}_{\mathrm{c}} \mathrm{dm}^{-3}\right) ; \mathrm{Al}=0,0\left(\mathrm{cmol}_{\mathrm{c}}\right.$ $\left.\mathrm{dm}^{-3}\right) ; \mathrm{H}=3,5\left(\mathrm{cmol}_{\mathrm{c}} \mathrm{dm}^{-3}\right) ; \mathrm{P}=5,6\left(\mathrm{mg} \mathrm{dm}{ }^{-3}\right) ; \mathrm{k}=$ $101,0\left(\mathrm{mg} \mathrm{dm}^{-3}\right) ; \mathrm{pH}=5,0\left(\mathrm{CaCl}_{2}\right)$; saturação por bases $51,80 \%$ e M.O. $=1,5 \mathrm{~g} \mathrm{~kg}^{-1}$. Foi realizada a dessecação sete dias antes da semeadura com $3 \mathrm{~L} \mathrm{ha}^{-1}$ de glifosato.

A semeadura foi realizada manualmente no dia 05/12/2011, sendo utilizada como adubação de semeadura a fórmula 4-30-10 (NPK) na dosagem de 350 $\mathrm{kg} \mathrm{ha}{ }^{-1}$. A emergência ocorreu em 11/12/2011. Realizou-se adubação em cobertura aos 20 dias após a emergência, com $90 \mathrm{~kg} \mathrm{ha}^{-1}$ de $\mathrm{N}$, e, para o controle de plantas invasoras, foi utilizado o herbicida atrazina na dose de 3,0 $\mathrm{L} \mathrm{ha}^{-1}$ aos 20 dias após a semeadura.

Utilizou-se o delineamento de blocos casualizados em esquema fatorial $2 \times 5$, sendo duas alturas de corte $(0,25$ e $0,50 \mathrm{~m})$ e cinco híbridos de milho (AGN30A95H, DKB390Y, DKB399Y, P3862H e TRUCK) com três repetições. As características dos híbridos estão na Tabela 1 . 
Tabela 1. Características dos híbridos utilizados no trabalho de pesquisa.

\begin{tabular}{lllll}
\hline Híbrido & Textura do grão & Cor do grão & Ciclo & Empresa \\
\hline AGN30A91H & Semi-duro & Alaranjado & Precoce & Morgan \\
DKB399Y & Semi-duro & Alaranjado & Semi-precoce & Dekalb \\
DKB390Y & Semi-duro & Alaranjado & Precoce & Dekalb \\
P3862H & Semi-duro & Amarelo & Precoce & Pioneer \\
TRUCK & Duro & Alaranjado & Precoce & Syngenta \\
\hline
\end{tabular}

Cada parcela foi composta por quatro linhas com cinco metros de comprimento e espaçamento de $0,85 \mathrm{~m}$. Para a avaliação, utilizou-se as duas linhas centrais, eliminando $0,50 \mathrm{~m}$ nas extremidades, e a população foi de 65.000 plantas $^{-1} \mathrm{a}^{-1}$ para todos os híbridos. As plantas foram cortadas na altura de 0,25 e $0,50 \mathrm{~m}$ em relação ao solo no estádio fenológico de grãos farináceos, no dia 20/03/2012, aos 105 dias após a semeadura. Imediatamente após o corte, foram pesadas em balança digital para determinação da produção de massa verde (PMV). Em seguida, foram picadas em tamanhos uniformes em ensiladeira estacionária e incubadas em silos experimentais de tubos de PVC, com capacidade para $2,5 \mathrm{~kg}$ de silagem, equipados com válvulas especiais para escape do gás do tipo "bunsen" e fundo com areia para retenção do chorume. Durante o enchimento dos silos experimentais foi realizada a compactação manual, tomando-se o cuidado de expulsar o máximo possível de ar para evitar a proliferação de fungos aeróbicos.

A abertura dos silos experimentais foi realizada no dia 18/11/2012, aos 235 dias após a ensilagem, sendo descartados de cinco a seis centímetros das porções inferior e superior, coletando em seguida as amostras de silagem, que foram secas em estufa de ventilação forçada até peso constante e moídas em moinho tipo Willey com peneira de $1 \mathrm{~mm}$. As amostras foram encaminhadas para o laboratório, onde foram analisados os teores de matéria seca (MS), fibra em detergente neutro (FDN), fibra em detergente ácido (FDA), proteína bruta $(\mathrm{PB})$ e $\mathrm{pH}$. As análises de MS, FDN, FDA e $\mathrm{pH}$ foram realizadas segundo procedimentos descritos por Silva e Queiroz (2002). Para as análises de nitrogênio amoniacal $\left(\mathrm{N}-\mathrm{NH}_{3}\right)$ foram retirados das silagens, com a ajuda de prensa hidráulica, $40 \mathrm{~mL}$ da fração líquida para posterior análise, seguindo a metodologia proposta por AOAC (1990).

Os dados foram submetidos à análise de variância e as médias comparadas pelo teste Tukey ao nível de 5\% de significância. As análises foram realizadas com auxílio do software R (R Core Team, 2010).

\section{Resultados e Discussão}

Não foi verificada interação significativa $(\mathrm{P}>0,05)$ entre os híbridos de milho e as alturas de corte para produção de massa verde (PMV), produção de massa seca (PMS), matéria seca (MS), proteína bruta (PB), fibra em detergente neutro (FDN), fibra em detergente ácido (FDA), nitrogênio amoniacal e pH entre os híbridos de milho e as duas alturas de corte das plantas. Todos os híbridos são de alta tecnologia, possuindo potencial genético para altas produtividades e apresentando características químico-bromatológicas semelhantes. Os dados de altura de espiga e de planta, produção de massa verde e produção de massa seca estão representados na Tabela 2.

Ocorreu diferença estatística $(\mathrm{P}<0,05)$ para as alturas de espiga e de planta (Tabela 2). Em relação à primeira espiga, os híbridos P3862H e DKB399Y (verificar espaçamento) foram os que atingiram maiores alturas que os demais, ao passo que os AGN30A95H e TRUCK apresentaram menor altura. Para a altura de planta, os híbridos DKB399Y e P3862H apresentaram-se como as plantas mais altas $(2,35 \mathrm{~m})$ e o cultivar TRUCK como as plantas de menor altura $(2,04 \mathrm{~m})$. Mesmo apresentando diferença estatística $(\mathrm{P}<0,05)$, os componentes agronômicos não interferiram nas demais variáveis analisadas: produção de massa verde e produção de massa seca. Santos et al. (2012), avaliando sete variedades de milho para a produção de silagem, encontraram resultados inferiores para altura de planta e altura de espiga em relação aos relatados nesta pesquisa. Esta variável contribuiu para o aumento de produção de matéria seca de silagem. Neumann et al. (2018), que trabalharam com os híbridos $\mathrm{P} 2530 \mathrm{H}, \mathrm{P} 30 \mathrm{R} 50 \mathrm{H}$ e $\mathrm{P} 30 \mathrm{~B} 39 \mathrm{H}$, encontraram diferença de altura de plantas cujos valores médios foram de 2,55, 2,52 e 2,37 m, respectivamente; observaram também diferença para a altura com médias de $1,25,1,28$ e $1,25 \mathrm{~m}$, respectivamente.

Segundo Domingues et al. (2013), plantas mais altas podem ser mais produtivas e contribuir com a produção de massa verde, mas isso não significa que a silagem produzida será de maior qualidade. No presente estudo, a altura não promoveu acréscimo na produção de massa verde. A altura de planta é uma característica importante para a redução das perdas por acamamento e sombreamento das folhas no terço inferior das plantas que permaneceram verdes por um período maior, contribuindo para a manutenção da qualidade do material a ser ensilado. Na presente pesquisa, a altura 
variou de 2,04 a 2,35 m e não foram observadas plantas acamadas no momento do corte. A produção de massa verde e produção de massa seca apresentaram médias de 40,2 e 13,1 t ha $^{-1}$, respectivamente, conforme apresentado na Tabela 2, e foram estatisticamente iguais para os híbridos e altura de corte, mostrando que os híbridos possuem alto potencial produtivo, independente da altura de corte. No trabalho desenvolvido por Guimarães et al. (2017), que trabalharam com o híbrido BG 7049, verificou-se produção de massa verde de $46.462 \mathrm{~kg} \mathrm{ha}^{-1}$ e produção de massa seca de $12.994 \mathrm{~kg}$ $\mathrm{ha}^{-1}$ no momento do corte para ensilagem, produtividades semelhantes às obtidas na presente pesquisa para a PMS.

Klein et al. (2018) trabalharam com quatro híbridos para produção de silagem (AS 1551 convencional, AS 1551 PRO2, AS 1656 PRO3 e AS 1696 PROX) e observaram que a produção de massa verde e a produção de massa seca não diferiram entre os híbridos, o mesmo observado na presente pesquisa (Tabela 2). Segundo os mesmos autores, os híbridos AS 1551 convencional, AS 1551 PRO2, AS 1656 PRO3 e AS 1696 PROX apresentaram boa capacidade produtiva. Assim, deve-se levar em conta na escolha do híbrido, além do preço de aquisição das sementes, as vantagens e as facilidades de manejo que ele proporcionará.

Para os teores de MS e composição bromatológica da matéria original (Tabela 3), não ocorreram diferenças significativas $(\mathrm{P}>0,05)$ para os híbridos e nem para as alturas de corte para silagem, com teores médios de 59,07, 28,68 e 8,22\% para FDN, FDA e PB, respectivamente.

Os teores médios de 33,50\% de MS para os híbridos e de $32,50 \%$ para a altura de corte proporcionam boa compactação e redução na quantidade de ar presente dentro do silo. As médias apresentadas na Tabela 3 para o teor de MS $(33,50 \%)$ estão de acordo com Ferreira et al. (2011), que relatam que a planta de milho deve ser colhida nos intervalos de 30 a $35 \%$ de MS para confecção de silagens e que a porcentagem de MS e de grãos na silagem de milho são afetadas substancialmente pelo estádio de desenvolvimento em que a planta de milho é colhida, além do cultivar utilizado. Pereira et al. (2007) citam que teores de MS acima de $35 \%$ dificultam a compactação do material ensilado e expulsão do ar, e teores abaixo de $28 \%$ proporcionam acréscimo na lixiviação, resultando, desta forma, na perda de nutrientes e na redução do material ensilado. Esse valor (33,50\% para MS) indica que no momento do corte nenhum cultivar apresentou umidade acima de $75 \%$, não favorecendo, deste modo, o desenvolvimento de bactérias do gênero Clostridium, que, de acordo com Almeida Filho et al. (1999), podem levar à perda de qualidade e valor nutritivo da silagem através da formação de ácido butírico.

O teor médio de FDN foi de 59,07\% e está dentro dos teores ideais para ensilagem, não havendo diferença estatística entre os híbridos. Esta variável está relacionada com o consumo da silagem pelo animal e o recomendado por Van Soest (1994), que preconiza valores de FDN em torno de $60 \%$ como sendo os ideais para melhor consumo pelos animais. Para a FDA, também não houve esta diferença, sendo os teores médios observados de $28,68 \%$ para os híbridos e de $28,55 \%$ para as alturas de corte no momento da ensilagem (Tabela 3). Estes valores estão de acordo com os teores encontrados por Rosa et al. (2004), que, avaliando três diferentes híbridos de milho, encontraram valores de FDN entre 55,76 e 57,99\%, e FDA entre 26,92 e 28,92\%. Segundo Van Soest (1994), a FDA está relacionada com a digestibilidade da matéria seca ingerida e o ideal é que estes teores sejam por volta de $30 \%$.

Tabela 2. Componentes agronômicos, produção de matéria verde (PMV) e produção de matéria seca (PMS) de híbridos de milho em duas alturas de corte.

\begin{tabular}{lcccc}
\hline Híbridos & Altura de espiga(m) & Altura de planta(m) & $\begin{array}{c}\text { PMV } \\
\left(\mathrm{t} \mathrm{ha}^{-1}\right)\end{array}$ & $\begin{array}{c}\text { PMS } \\
\left(\mathrm{t} \mathrm{ha}^{-1}\right)\end{array}$ \\
\hline AGN30A95H & $1,04 \mathrm{c}$ & $2,13 \mathrm{~b}$ & 39,6 & 12,4 \\
DKB399Y & $1,22 \mathrm{a}$ & $2,35 \mathrm{a}$ & 40,9 & 13,5 \\
DKB390Y & $1,11 \mathrm{~b}$ & $2,08 \mathrm{~b}$ & 41,1 & 13,6 \\
P3862H & $1,31 \mathrm{a}$ & $2,35 \mathrm{a}$ & 43,7 & 12,4 \\
TRUCK & $1,05 \mathrm{bc}$ & $2,04 \mathrm{~b}$ & 36,0 & 13,1 \\
\hline MÉDIAS & 1,14 & 2,19 & 40,2 & PMS \\
\hline Altura de Corte $(\mathrm{m})$ & - & - & $\left.\mathrm{t}^{-1}\right)$ \\
\hline 0,25 & - & - & $\left(\mathrm{t} \mathrm{ha} \mathrm{a}^{-1}\right)$ & 14,0 \\
0,50 & - & - & 42,0 & 12,3 \\
\hline MÉDIAS & - & - & 38,5 & 13,1 \\
\hline CV\% & 4,74 & 4,92 & 40,2 & 20,4 \\
\hline
\end{tabular}

Médias seguidas de letras iguais na mesma coluna não diferem entre si pelo teste Tukey a 5\% de probabilidade. 
Tabela 3. Composição bromatológica da matéria original no momento da ensilagem dos híbridos de milho analisados.

\begin{tabular}{lcccc}
\hline Cultivar & MS & FDN & FDA & PB \\
\hline & $(\%)$ & $-----1,-19$ & 7,97 \\
AGN30A95H & 35,25 & 57,59 & 28,40 & 8,35 \\
DKB390Y & 33,13 & 59,81 & 28,37 & 8,25 \\
DKB399Y & 33,14 & 59,38 & 28,70 & 8,26 \\
P3862H & 31,38 & 59,76 & 28,79 & 8,29 \\
TRUCK & 34,62 & 58,84 & 29,15 & 8,22 \\
\hline MÉDIAS & 33,50 & 59,07 & 28,68 & PB \\
\hline Altura de Corte $(m)$ & MS & FDN & FDA & 8,30 \\
\hline 0,25 & 33,30 & 59,02 & 28,56 & 8,15 \\
0,50 & 31,70 & 59,13 & 28,55 & 8,22 \\
\hline MÉDIAS & 32,50 & 59,07 & 28,55 & 3,52 \\
\hline CV $(\%)$ & 12,52 & 2,66 & 3,06 & \\
\hline
\end{tabular}

Médias seguidas de letras iguais na mesma coluna não diferem entre si pelo teste Tukey a 5\% de probabilidade.

Na presente pesquisa, o teor médio de PB foi $8,22 \%$ (Tabela 3). Valores de PB variando de 6 a $9 \%$ são esperados para híbridos destinados para silagem, conforme relatos de Jaremtchuk et al. (2005). Estes resultados indicam que todos os híbridos possuem boas características produtivas e bromatológicas a serem usadas para ensilagem.

Os teores de PB encontrados por Pereira et al. (2007) ficaram entre 6,19 e 6,90 no material no momento da ensilagem e foram inferiores aos obtidos na presente pesquisa $(8,22 \%)$, conforme apresentados na Tabela 3. Araújo et al. (2012) não observaram diferença significativa para os teores de PB $(7,95 \%)$ em silagem de vários híbridos de milho.

No trabalho desenvolvido por Neumann et al. (2018), que trabalharam com três híbridos (P2530H, P30R50H e P30B39H), verificou-se teores de PB médio de $6,52 \%$, bem abaixo dos obtidos na presente pesquisa $(8,22 \%)$, conforme Tabela 3. A diferença entre os resultados obtidos por Neumman et al. (2018) e a presente pesquisa pode ser explicada pelas proporções ocupadas pela FDN $(64,14 \%)$ e pela FDA $(33,15 \%)$, que foi bem acima da apresentada na Tabela 3 .

A composição químico-bromatológica das silagens dos diferentes híbridos de milho é apresentada na Tabela 4. Com base nestes dados, observa-se que os teores MS, FDN, FDA, PB, nitrogênio amoniacal (N$\left.\mathrm{NH}_{3}\right)$ e $\mathrm{pH}$ não diferiram estatisticamente $(\mathrm{P}>0,05)$ para os cinco híbridos estudados e as alturas de corte.

O teor médio de MS na silagem foi de 33,39\% para os híbridos (Tabela 4). Estes teores contribuem para a conservação do material ensilado e quando bem compactado inibe o desenvolvimento de organismos que depreciam a qualidade da silagem, mantendo assim seu valor nutricional. Os resultados encontrados na Tabela 4 estão de acordo com os verificados por Pinto et al. (2010), que, avaliando doze híbridos de milho, obtiveram variação de MS de 33,2\% (TRAKTOR) e $38,2 \%$ (AGN-3150).
Os teores de MS não foram influenciados $(\mathrm{P}>0,05)$ pela altura de corte das plantas para silagem, portanto, as duas alturas podem ser utilizadas para corte de híbridos de milho destinados à produção de silagem. Da mesma forma, as alturas da planta e da espiga não exerceram influência na MS. Araújo et al. (2012) avaliaram a silagem de seis híbridos de milho e verificaram que não ocorreu diferença significativa de MS entre os híbridos, cujos teores variaram de 28,8 a $34,5 \%$, valores considerados adequados para melhor compactação e conservação da silagem.

A variável de FDN presente na MS apresentou teor médio de 55,50\%, que foi estatisticamente igual para híbridos e altura de corte (Tabela 4), proporção está adequada para o consumo de silagem pelos animais. Valores encontrados por Almeida Filho et al. (1999) variaram de 58,13 a 63,39\% para os híbridos Embrapa 206 e Agroceres 1050. Caetano et al. (2011) observaram teores variando entre 43,86 e 51,87\% para os híbridos C333 e Dina 657, respectivamente. Os mesmos autores verificaram diferença significativa $(\mathrm{P}<0,05)$ para altura de corte $(5 \mathrm{~cm}$ acima do solo e $5 \mathrm{~cm}$ abaixo da primeira espiga), com valores de 51 e $42,83 \%$ para as duas alturas, respectivamente, sendo esses teores estatisticamente iguais para a silagem de onze híbridos de milho.

A FDN é o parâmetro que se correlaciona com o consumo voluntário de matéria seca pelo animal (Van Soest, 1994), agindo como fator limitante à ingestão de forragem. Este efeito é maior quando a FDN se encontra acima de $60 \%$. No entanto, o consumo de fibras pelos ruminantes é importante para a produção de ácidos graxos voláteis durante a fermentação ruminal, que se tornam importantes fontes de energia para os microorganismos presentes no rúmen. Assim, no presente trabalho (Tabela 4), todos os híbridos estudados apresentaram FDN dentro da faixa ideal para estimular o consumo de MS pelo animal. Para as alturas de corte, a FDN não apresentou diferença significativa $(\mathrm{P}>0,05)$. 
Tabela 4. Composição químico-bromatológica de silagem de híbridos de milho ensilados sob duas alturas de corte.

\begin{tabular}{|c|c|c|c|c|c|c|}
\hline Híbridos & $\begin{array}{l}\text { MS } \\
(\%) \\
\end{array}$ & $\begin{array}{c}\text { FDN } \\
(\%)\end{array}$ & $\begin{array}{l}\text { FDA } \\
(\%)\end{array}$ & $\begin{array}{l}\mathrm{PB} \\
(\%)\end{array}$ & $\begin{array}{c}{\mathrm{N}-\mathrm{NH}_{3}} \\
\left(\mathrm{mg} 100^{-1} \mathrm{~mL}\right)\end{array}$ & $\begin{array}{c}\mathrm{pH} \\
-\end{array}$ \\
\hline AGN30A95H & 35,47 & 55,29 & 27,27 & 7,21 & 1,90 & 3,68 \\
\hline DKB399Y & 32,61 & 55,12 & 27,25 & 7,33 & 1,91 & 3,64 \\
\hline DKB390Y & 32,71 & 56,22 & 27,34 & 7,30 & 1,91 & 3,69 \\
\hline P3862H & 31,76 & 55,35 & 26,93 & 7,41 & 1,86 & 3,73 \\
\hline TRUCK & 34,41 & 55,54 & 26,00 & 7,45 & 1,91 & 3,75 \\
\hline MÉDIAS & 33,39 & 55,50 & 26,95 & 7,34 & 1,89 & 3,69 \\
\hline Altura de corte (m) & $\begin{array}{l}\text { MS } \\
(\%)\end{array}$ & $\begin{array}{c}\text { FDN } \\
(\%)\end{array}$ & $\begin{array}{l}\text { FDA } \\
(\%)\end{array}$ & $\begin{array}{l}\text { PB } \\
(\%)\end{array}$ & $\begin{array}{c}\mathrm{N}-\mathrm{NH}_{3} \\
(\%)\end{array}$ & $\begin{array}{c}\mathrm{pH} \\
-\end{array}$ \\
\hline 0,25 & 32,66 & 55,97 & 27,09 & 7,34 & 1,90 & 3,67 \\
\hline 0,50 & 34,14 & 55,04 & 26,83 & 7,34 & 1,80 & 3,72 \\
\hline MÉDIAS & 33,40 & 55,50 & 26,96 & 7,34 & 1,85 & 3,69 \\
\hline $\mathrm{CV}(\%)$ & 6,24 & 2,48 & 3,16 & 3,07 & 4,06 & 2,7 \\
\hline
\end{tabular}

Médias seguidas de letras iguais na mesma coluna não diferem entre si pelo teste Tukey a $5 \%$ de probabilidade.

Os valores de FDA obtidos nesta pesquisa (26,95\%), apresentados na Tabela 4, estão próximos do preconizado por Mertens (1994) quando estabelece o valor máximo de $30 \%$ como sendo o ideal para que ocorra maior consumo de forragem e melhor digestibilidade da matéria seca consumida. No trabalho desenvolvido por Pereira et al. (2007) e Araújo et al. (2012) não foram observadas diferenças significativas entre seis híbridos de milho para as variáveis FDN e FDA, resultados que corroboram com a presente pesquisa.

O teor médio de PB foi de 7,34\% para os híbridos de milho, como verificado na Tabela 4, valor este adequado para silagem de milho, não diferindo entre os híbridos nem entre as alturas de corte. $\mathrm{Na}$ pesquisa desenvolvida por Oliveira et al. (2011) não foi observada diferença significativa $(\mathrm{P}>0,05)$ de $\mathrm{PB}$ entre os cinco híbridos avaliados e as três alturas de corte com teores variando de 8,13 (DKB 747) a 8,61\% (AS 32), cujos valores estão acima dos encontrados neste estudo, que apresentou valor médio de 7,34\%.

Van Soest (1994) afirma que a forrageira que contêm teores de PB abaixo de 7\% limita a digestão da mesma devido aos baixos níveis de $\mathrm{N}$ para os microorganismos do rúmen, reduzindo sua população e influenciando na redução da ingestão e na digestibilidade de matéria seca. Desta forma, teor mais alto de PB é necessário para suprir as exigências dos microrganismos ruminais, favorecendo assim seu desenvolvimento.

Ao analisar os dados de $\mathrm{N}^{-\mathrm{NH}_{3}}$ (Tabela 4) da fração líquida das silagens, observou-se que todos os híbridos obtiveram resultados não significativos estatisticamente, apresentando valor médio de $1,89 \mathrm{mg} 100^{-1} \mathrm{~mL}$ (Tabela 4). Este teor demonstra que a fermentação foi bem efetuada pelos microrganismos, mantendo a qualidade da silagem. Os valores de $\mathrm{pH}$ não apresentaram diferença estatística $(\mathrm{P}>0,05)$ e a média constatada nas silagens dos híbridos de milho foi de 3,69, sendo considerada de ótima qualidade para incrementar a dieta animal e ainda promover a inibição do crescimento de microrganismos anaeróbicos indesejáveis. $\mathrm{O} \quad \mathrm{N}$ amoniacal e o pH têm relação direta com a fermentação ocorrida dentro do silo e são parâmetros de avaliação da qualidade ocorrida durante a fermentação. Os teores apresentados na Tabela 4 são indicativos de que os processos fermentativos ocorridos dentro do silo foram adequados, o que manteve o valor nutricional da silagem. No trabalho desenvolvido por Araújo et al. (2012), não foram observadas diferenças significativas entre seis híbridos de milho para $\mathrm{N}_{-} \mathrm{NH}_{3}$ e $\mathrm{pH}$, resultados que corroboram com a presente pesquisa. Segundo McDonald et al. (1991), a faixa considerada ideal de $\mathrm{pH}$ de silagem situa-se entre 3,6 e 4,2 para promover uma eficiente conservação da massa ensilada. Rosa et al. (2004) avaliaram em sua pesquisa as características químico-bromatológicas e fermentativas da silagem de três híbridos de milho (AG-5011, XL-344 e C-806), obtendo valor médio de $\mathrm{pH}$ de 3,41 .

Em síntese, a altura de corte não influenciou na qualidade da silagem, o que é interessante para o produtor, pois este poderá cortar as plantas de milho com menor altura em relação ao solo, o que resultará em maior produtividade, sem ocorrer qualquer prejuízo na qualidade da silagem produzida.

\section{Conclusões}

Os cinco híbridos de milho avaliados podem ser utilizados para produção de silagem. O corte da planta de milho com altura de $0,25 \mathrm{~m}$ em relação ao solo não prejudica a qualidade da silagem produzida.

\section{Referências Bibliográficas}

Almeida Filho, S.L., Fonseca, D.M., Garcia, R.; Obeid, J.A., Oliveira, J.S. 1999. Características agronômicas de híbridos de milho (Zea mays L.) e qualidade dos componentes da silagem. Revista Brasileira de Zootecnia, Viçosa, 28, 7-13. 
Araújo, K.G., Villela, S.D.J., Leonel, F.P., Costa, P.M., Fernandes, L.O., Tamy, W.P., Andrade, V.R. 2012. Yeld and quality of silage of maize hybrids. Revista Brasileira de Zootecnia, Viçosa, 41, 15391544.

AOAC. 1990. Official Methods of Analysis of the Association of Official Analytical Chemists. Washington, Association of Official Analytical Chemistsa, $15^{\text {th }}$ ed., pp.369-406.

Ballard, C.S., Thomas, E.D., Tsang, D.S., Mandebvu, P., Sniffen, C.J., Endres, M.I., Carter, M.P. 2001. Effect of corn silage hybrid on dry matter yield, nutrient composition, in vitro digestion, intake by dairy heifers, and milk production by dairy cows. Journal of Dairy Science, Champaign, 84, 442-452. DOI: https://doi.org/10.3168/jds.S0022-0302(01)74494-3.

Caetano, H., Oliveira, M.D.S., Freitas Júnior, J.E., Rergo, A.C., Carvalho, M.V., Renno, F.C. 2012. Bromatological evaluation of eleven corn cultivars harvested at two cutting heights. Revista Brasileira de Zootecnia, Viçosa, 41, 11-17.

Caetano, H., Oliveira, M.D.S., Freitas Júnior, J.E., Rergo, A.C., Carvalho, M.V., Renno, F.C. 2011. Nutritional characteristics and in vitro digestibility of silages from different corn cultivars harvested at two cutting heights. Revista Brasileira de Zootecnia, Viçosa, 40, 708-714.

Domingues, A.N., Abreu, J.G., Caneppele, C., Reis, R.H.P., Behling Neto, A., Almeida, C.M. 2013. Agronomic characteristics of corn hybrids for silage production in the State of Mato Grosso, Brazil. Acta Scientiarum. Animal Sciences, Maringá, 35, 7-12. Doi: 10.4025/actascianimsci.v35il.15592

Ferreira, G.D.G., Barrière, Y., Emile, J.C., Jobim, C.C., Almeida, O.C. 2011. Valor nutritivo da silagem de dez híbridos de milho. Acta Scientiarum Animal Sciences, Maringá, 33, 255-260.Doi: 10.4025/actascianimsci.v33i3.9890

Gimenes, A.L.G., Mizubuti IY, M.F.B., Pereira, E.S., Ribeiro, E.L.A., Mori, R.M. 2006. Composição química e estabilidade aeróbia em silagem de milho preparadas com inoculantes bacteriano e/ou enzimático. Acta Scientiarum Animal Sciences, Maringá, 28, 153-158. DOI: 10.4025/actascianimsci.v28i22.640

Guimarães, F. S., Ciappina, A. L., Anjos, R. A. R., Silva, A., Pela, A. 2017. Consórcio guandu-milho-braquiária para integração lavoura-pecuária. Revista de Agricultura Neotropical, Cassilândia, 4, 22-27.

Jaremtchuk, A.R., Jaremtchuk, C.C., Baglioli, B., Medrado, M.T., Kozlowski, L.A., Costa, C., Madeira, H.M.F. 2005. Características agronômicas e bromatológica de vinte genótipos de milho (Zea mays L.) para silagem na região leste paranaense. Acta Scientiarum. Animal Sciences, Maringá, 27, 181-188.DOI: 10.4025/actascianimsci.v27i2.1220

Johnson, L.M., Harrison, D., Davidson, D., Robutti, J.L., Swift, M., Mahanna, W.C., Shinners, K. 2002. Corn silage management I: Effects of hybrid, maturity, and mechanical processing on chemical and physical characteristics. Journal Dairy Science, Champaign, 85, 833-853. DOI: https://doi.org/10.3168/jds.S0022-0302(02)74143-X

Klein, J.L., Viana, A.F.P., Martini, P.M., Adams, S.M., Gusatto, C., Bona, R.A., Rodrigues, L.S., Alves Filho, D.C., Brondani, I.L. 2018. Desempenho produtivo de híbridos de milho para produção de silagem de planta inteira. Revista Brasileira de Milho e Sorgo, Sete Lagoas, 17, 101-110.

Mcdonald, P., Henderson, A.R., Heron, S.J.E. 1991. The biochemistry of silage. s.1.: Scholium International 155p.
Mertens, D.R. 1994. Regulation of forage intake. In: Forage quality, evaluation and utilization. Madison: American Society of Agronomy, pp.450-493.

Neumann, M., Muhlbach, P.R.F., Restle, J., Ost, P.R., Lustosa, S.B.C., Falbo, M.K. 2007. Ensilagem de milho (Zea mays, L.) em diferentes alturas de corte e tamanho de partículas: produção, composição e utilização na terminação de bovinos em confinamento. Revista Brasileira de Milho e Sorgo, Sete Lagoas, 6, 379-397.

Neumann, M., Poczynek, M., Leão, G.F.M., Figueira, D.N., Souza, A.M. 2018. Desempenho de híbridos de milho para silagem cultivados em diferentes locais com três densidades populacionais. Revista Brasileira de Milho e Sorgo, Sete Lagoas, 17,49-62.

Oliveira, M.R., Neumann, M., Ueno, R.K., Neri, J., Marafon, F. 2013. Avaliação das perdas na ensilagem de milho em diferentes estádios de maturação. Revista Brasileira de Milho e Sorgo, Sete Lagoas, 12, 319-325.

Oliveira, F.C.L., Jobim, C.C., Silva, M.S., Calixto Juniior, M., Bumbieris Junior, V.H., Roman, J. 2011. Produtividade e valor nutricional da silagem de híbridos de milho em diferentes alturas de colheita. Revista Brasileira de Zootecnia, Viçosa, 40, 720-727.

Pereira, E.S., Mizubuti, I.Y., Pinheiro, S.M., Villarroel, A.B.S., Clementino, R.H. 2007. Avaliação da qualidade nutricional de silagens de milho (Zea mays, L). Revista Caatinga, Mossoró, 20, 08-12.

Pinto, A.P., Lançanova, J.A.C., Lugão, S.M.B., Roque, A.P., Abrahão, J.J.S., Oliveira, J.S., Leme, M.C.J., Mizubuti, I.Y. 2010. Avaliação de doze híbridos de milho (Zea mays L.) para silagem. Semina: Ciências Agrárias, Londrina, 31, 1071-1078.

R Development Core Team. R: A language and environment for statistical computing. R Foundation for Statistical Computing, Vienna, Austria. ISBN 3-900051-07-0, URL http://www.Rproject.org. 2010.

Rosa, J.R.P., Silva, J.H.S., Restle, J., Pascoal, L.L., Brondani, I.L., Alves Filho, D.C., Freitas, A.K. 2004. Avaliação do Comportamento Agronômico da Planta e Valor Nutritivo da Silagem de Diferentes Híbridos de Milho (Zea mays, L.). Revista Brasileira de Zootecnia, Viçosa, 33, 302-312.

Santos, R.D., Pereira, L.G.R., Neves, A.L.A., Azevedo, J.A.G., Moraes, S.A., Costa, C.T.F. 2012. Características agronômicas de variedades de milho para produção de silagem. Acta Scientiarum: Animal Sciences, Maringá, 32, 367-373. doi: 10.4025/actascianimsci.v32i4.9299.

Santos, M. V. F., Gómez Castro, A. G., Perea, J. M., Garcia, A., Guim, A., Pérez Hernández, M. 2010. Fatores que afetam o valor nutritivo da silagem de forrageiras tropicais. Archivos de Zootecnia, Córdoba, 59, 25-43.

Silva, D.J., Queiroz, A.C. 2002. Análise de Alimentos: Métodos químicos e biológicos. 3.ed. Viçosa: Ed. UFV.

Van Soest, P.J. 1994. Nutritional ecology of the ruminant. 2. Ed. New York: Cornell University Press, 476p.

Zopollatto, M., Nussio, L.G., Mari, J.M., Schjmidt, P., Duarte, A.P., Mourão, G.B. 2009. Alterações na composição morfológica em função do estádio de maturação em híbridos de milho para produção de silagem. Revista Brasileira de Zootecnia, Viçosa, 38, 452-461. 